\title{
Perú: del estancamiento económico a la reformulación del modelo de desarrollo (1975-2004)
}

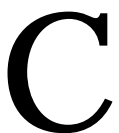
on un ingreso per cápita de 2150 dólares y una población estimada en $27 \mathrm{mi}$ llones de habitantes en 2003, Perú está clasificado por el Banco Mundial en la categoría de países de ingreso medio bajo severamente endeudados. Es miembro, desde su creación en 1969, del Pacto Andino, renovado en 1996 en una Comunidad Andina de Naciones (CAN), que incluye hoy, además de Perú, a Bolivia, Colombia, Ecuador y Venezuela. En 2004 Perú se asoció al Mercado Común del Sur (MERCosur) y se encuentra negociando un área de libre comercio con este acuerdo regional, con la finalidad de integrar más adelante la proyectada Área de Libre Comercio de América del Sur, que reuniría los países miembros del MERcosur y de la can, así como Chile. En noviembre de 1998, Perú se incorporó al Mecanismo de Cooperación de Asia Pacífico (APEC, por su sigla en inglés), que reúne 21 economías ribereñas del Pacífico.

Esta nación andina posee un territorio de 1.3 millones de $\mathrm{km}^{1}$, que se extiende desde la costa Pacífica desértica hasta la selva amazónica cruzando las elevadas cordilleras andinas; se encuentra dotada de una gran variedad de recursos naturales que determinó su temprana inserción en la economía internacional en tanto exportador de materias primas. Heredero de un rico conjunto de civilizaciones prehispánicas, Perú recibió desde la época colonial aportaciones poblacionales diversas - africanos esclavizados, europeos y, en la era republicana, asiáticos originarios principalmente de China y Japón-que se agregaron a su población original y constituyen hoy un complejo mosaico marcado por hondas diferencias y desigualdades de orden social y racial.

* Profesora investigadora del Departamento de Estudios del Pacífico, de la Universidad de Guadalajara, e investigadora del SNI.
Desde su independencia en 1824, Perú ha pasado por numerosos períodos de inestabilidad y dificultades económicas y políticas, y las últimas décadas del siglo XX constituyen el más reciente episodio de esta naturaleza. En efecto, el país experimentó en 1976 una crisis de deuda externa temprana que desencadenó un largo período de estancamiento con inflación creciente asociado, desde 1980, a la progresiva extensión a todo el territorio nacional de la insurrección del grupo armado conocido bajo el nombre de Sendero Luminoso. Es a partir de 1992, después de una larga sucesión de fallidos programas de ajuste económico, asociados a muy elevados costos sociales, que las autoridades peruanas lograron estabilizar la economía, introducir reformas estructurales y retomar el control político-militar del país.

Este texto se propone revisar la evolución de la economía peruana a lo largo de los últimos treinta años y analizar algunas de sus características salientes. Para ello, se presentarán en un primer momento los rasgos esenciales y la evolución histórica de la economía, examinándose luego el largo proceso de estancamiento con inflación creciente y la difícil estabilización que experimentó entre la segunda mitad de los años setenta e inicios de los noventa. Por último, se discutirán brevemente la evolución y las perspectivas de su estructura productiva y de su comercio exterior.

\section{La economía de Perú: rasgos generales y antecedentes históricos}

Esta sección presentará de manera sintética las características macroeconómicas de Perú, se hará una descripción breve de sus recursos naturales y se reseñarán los rasgos salientes de su historia económica. 
La economía peruana en 2003: breve presentación macroeconómica

En el concierto latinoamericano, Perú figura en el grupo de economías de tamaño medio; medida en términos de producto interno bruto ( $\mathrm{PIB})$ expresado en dólares, se ubica en la séptima posición después de México, Brasil, Argentina, Venezuela, Colombia y Chile. Si consideramos el ingreso nacional bruto (INB) per cápita en dólares, la economía peruana se sitúa en el mismo rango, después de las economías relativamente más ricas de México, del Cono Sur -Argentina, Chile y Uruguay-, y de Venezuela, y delante de sus demás socios del área andina (ver gráfica 1).

En 2002 la economía peruana creció más rápido que los demás países de América Latina (4.9\% contra $0.5 \%$ en promedio), y mantuvo este buen desempeño macroeconómico relativo, acompañado de una tasa de inflación baja (1.5\% y $2.5 \%$ respectivamente en $2002-2003$ ) hasta 2004. En este último año, el alza de los volúmenes exportados por Perú y la mejoría de sus precios internacionales han dinamizado la economía, a la vez que permitían equilibrar la cuenta corriente. Como lo veremos más adelante, la composición de las exportaciones peruanas, donde predominan los bienes primarios, en especial los mineros, y los productos con elevadas economías de escala e intensivos en recursos naturales, relaciona este último desarrollo con la fuerte demanda de estos bienes que emana de Asia.

Ahora bien, los indicadores socioeconómicos reunidos en el cuadro 1 muestran - paradójicamente si tomamos en cuenta la historia económica de largo plazo del paísuna economía poco abierta al comercio inter- nacional: la suma de exportaciones e importaciones representaban $33.8 \%$ del PIB en 2002, una cifra menor que el promedio latinoamericano $(39.4 \%)$, que es a su vez ampliamente inferior al promedio de economías en desarrollo $(58.2 \%) .^{2}$ En consecuencia, el servicio de la deuda externa (28 105 millones de dólares en 2002) absorbía una proporción significativa de los ingresos por exportación de bienes y servicios: $23.8 \%$ en 2003. Tanto la inversión como el ahorro se establecían en un nivel de $18 \%$ del PIB en 2002 , relativamente bajo en términos internacionales pero similar a lo observado en la mayoría de los países de Centro y Sudamérica - un rasgo que plantea problemas de sostenibilidad de un crecimiento económico dinámico en el largo plazo-.

La composición del valor agregado y del empleo mostraban la predominancia del sector servicios, que absorbía $74.5 \%$ de la población activa en 2002 y generaba $63.6 \%$ del valor agregado. Veremos que este sector, que incluye actividades comerciales de sobrevivencia, se ha convertido en las últimas décadas en el mayor receptor de población activa subempleada, al reducirse las oportunidades de empleo en el sector manufacturero. Finalmente, con $54 \%$ de su población bajo la línea de pobreza, ${ }^{3}$ Perú se caracteriza por una gran desigualdad en la distribución del ingreso y de la riqueza: en 2002, el quintil superior recibía $53.2 \%$ del ingreso total, contra $2.9 \%$ para el quintil inferior.

\section{Territorio y recursos naturales}

El territorio de Perú está constituido por tres grandes regiones naturales de desigual importancia (ver mapa). Las llanuras costeras, que reciben muy escasas precipitaciones, alternan las zonas desérticas con los oasis creados al- 


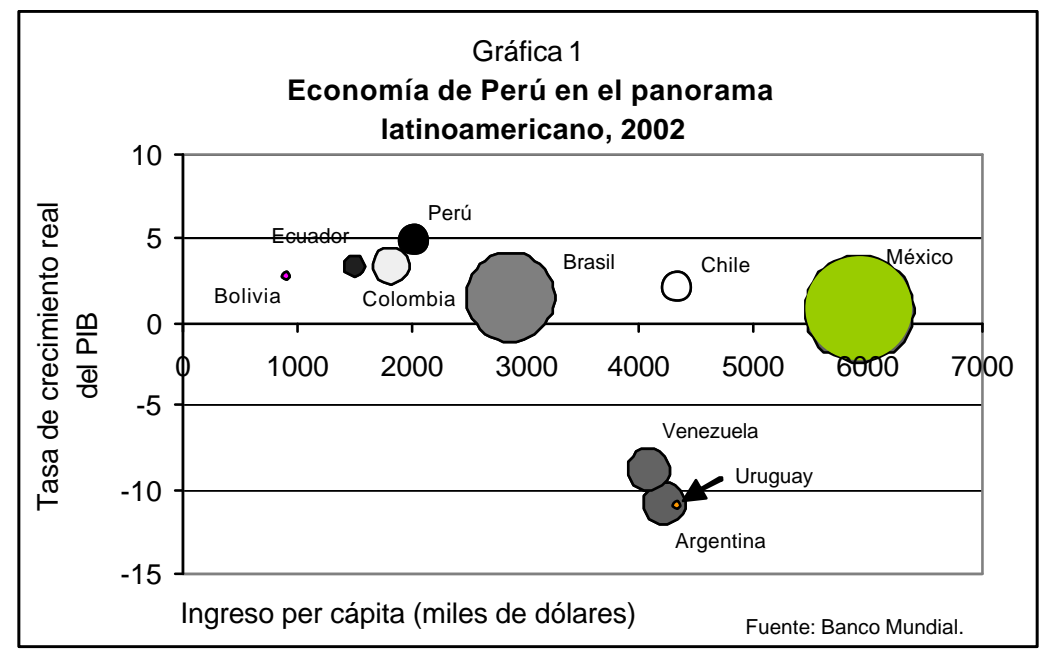

rededor de los ríos que descienden de las cordilleras andinas, donde se asentaron las principales poblaciones. Esta región, que solo representa $12 \%$ de la superficie del país, concentra la mayoría de las actividades económicas a la vez que alberga una elevada proporción de la población y las ciudades más importantes, en primer lugar la capital, Lima. La producción agrícola, favorecida por la fertilidad de las tierras, tropieza con las necesidades de riego y la escasez de agua. Se concentró tradicionalmente en los cultivos de algodón, caña de azúcar y arroz, complementados por una variedad de otras producciones de frutas y verduras. Esta región cuenta con pocos recursos minerales, con la excepción de yacimientos petroleros, ubicados en el extremo norte, explo- tados durante el siglo veinte y que se encuentran ahora prácticamente agotados.

Las cordilleras andinas y la selva amazónica, que constituyen la mayoría del territorio peruano, comparten grandes dificultades de acceso que obstaculizan seriamente su incorporación plena a la economía nacional. La sierra, antigua cuna de la civilización andina, cubre $28 \%$ del territorio del país y posee tierras de bajo rendimiento, a la vez que concentra la mayoría de los recursos minerales del país, algunos de los cuales hicieron la fama de riqueza natural que Perú ostentó desde la época colonial: oro, plata, cobre, zinc, plomo. La región selvática del bosque tropical húmedo es la más extensa (60\% del territorio)

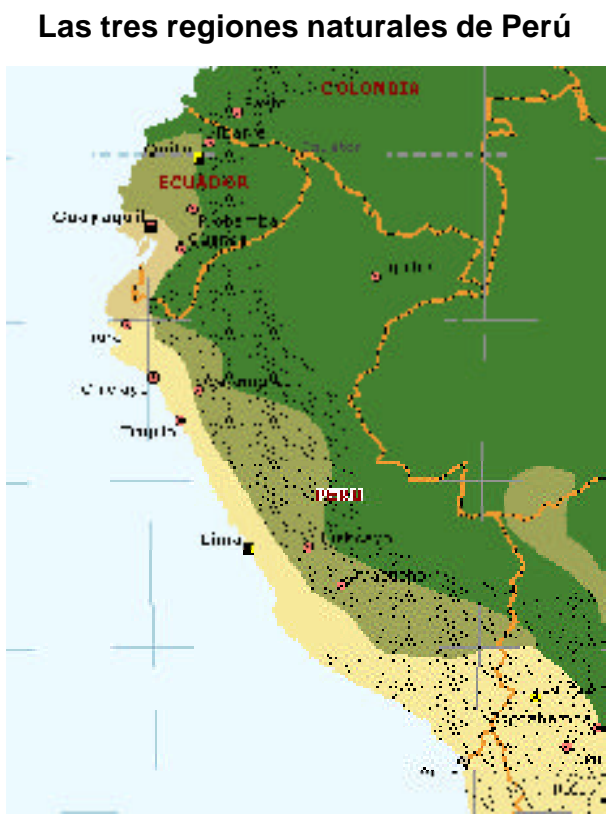


Cuadro 1

Indicadores socioeconómicos de Perú, 2002

1. Territorio, miles $\mathrm{km}^{2}$

2. Población, miles

Habitantes por $\mathrm{km}^{2}$, personas

Esperanza de vida al nacer, años

Tasa de mortalidad infantil, por 1000 nacidos vivos

Mujer en la fuerza de trabajo (\% del total)

Población mayor de 65 años (\% del total)

Promedio de años de escolaridad

3. Economía

Ingreso Nacional Bruto (INB, mill. dls.)

INB per cápita, dólares

INB per cápita, dólares internacionales

INB crecimiento promedio anual (1990-2002)

Agricultura en el PIB (\%)

Población activa, cifras en millones (dato 2001)

En la agricultura (\%)

En la industria (\%)

En los servicios (\%)
1,280

26.7

20.8

70

30

35.3

4.9

7.6

56,500

2,113

5,010

4.1

9

10.1

8.5

17

74.5

ND

18.8

18

11.1

Inflación promedio anual, 1993-2003 (\%)

7,723

21

16.5

8.4

7,417

13

17.3

3.7

28,105

1,010

781

Turistas al exterior (miles de personas, dato de 2001

874

152.3

43

2.5

49.8

53.2

2.9

Ingreso o consumo del $20 \%$ más pobre de la población (\%)

Fuente: Banco Mundial, World Bank Atlas 2003 y 2004, World Development Indicators 2004, Peru at a glance (9/30/04) y Peru Data Profil, FMI, International Financial Statistics. 
y la menos poblada y conocida del país. Parte de esta región estuvo vinculada al auge del caucho de finales del siglo XIX e inicios del XX.

La historia económica de Perú desde la independencia hasta la década de los setenta: auges exportadores y crisis

Incorporado por primera vez en la economíamundo eurocéntrica en tanto territorio colonial, Perú ha mantenido desde estos inicios forzados y hasta la actualidad su condición de exportador de materias primas o de procesados intensivos en recursos naturales. Desde su independencia hasta la década de los setenta del siglo pasado, aplicó con pocas interrupciones una política de economía abierta. En una obra dedicada al crecimiento económico de largo plazo de Perú, Thorp y Bertram distinguen tres grandes ciclos exportadores en aproximadamente ciento cincuenta años de vida republicana del país. ${ }^{4}$

El primer auge exportador se basó en el guano, utilizado como fertilizante en la agricultura occidental, y duró aproximadamente cincuenta años, iniciándose en 1830 y terminando con la guerra del Pacífico (1879-1881) que opuso Bolivia y Perú a Chile, guerra en la cual venció este último y que marcó la peor crisis de la historia del Perú independiente. ${ }^{5}$

El segundo período de elevado crecimiento de las exportaciones inició en las dos ultimas décadas del siglo XIX y se fundamentó sobre una canasta más amplia y variable de productos, tanto de origen agrícola, con el algodón y el azúcar provenientes de la costa, la lana de la sierra sur y el caucho de la selva amazónica, como de carácter extractivo, con el petróleo de la costa norte y los minerales (cobre y plata) de la sierra. La crisis económica mundial de los años treinta puso fin a este auge exportador.

Finalmente, el último ciclo exportador peruano se inició con el final de la crisis de los treinta y terminó con otra recesión mundial, la de mediados de los setenta, que suscitó el desplome de sus precios de exportación. Se apoyó inicialmente en la mezcla de productos del período anterior, la que fue modificándose a favor de los minerales (cobre, plata, hierro, zinc y plomo) y de los productos pesqueros, decayendo las exportaciones agrícolas y las petroleras conforme iba subiendo la demanda interna.

Cada uno de los auges exportadores fue acompañado por políticas de libre-cambio y se apoyó ampliamente en la inversión extranjera. Su finalización implicó cada vez para el país una grave crisis económica iniciada por problemas de balanza de pagos y de deuda externa y seguida de restricción del gasto interno, inestabilidad política cambios de gobierno así como un cuestionamiento general del modelo primario-exportador. Estos períodos de crisis impulsaron cambios en el rumbo de la política económica, que incorporaron una mayor intervención del gobierno y esfuerzos para crear fuentes internas de crecimiento autosostenido y disminuir el grado de dependencia de la economía de exportación. Sin embargo, estas innovaciones en las políticas económicas no fueron exitosas.

Las restricciones externas propias del momento de crisis en la actividad exportadora, que acotaron severamente el margen de maniobra de las nuevas autoridades, combinadas con la falta de consistencia de las propias propuestas reformadoras hicieron que los dos primeros intentos de modificación del modelo, en 1879 y 1930, tuvieran una vida corta; el último, iniciado en los años cincuenta, si bien fue más duradero, no logró resolver los problemas estructurales de la economía.

En el largo plazo, el modelo de desarrollo peruano basado en las exportaciones primarias solo sustentó una tasa promedio de crecimiento real baja, estimada por Thorp y Bertram en alrededor de $1 \%$ anual per cápita ${ }^{6}$ y contribuyó a empeorar la desigual distribución del ingreso. Durante las fases de auge, el éxito y la rentabilidad comparativamente más alta del sector exportador, así como la amplia disponibilidad de divisas, desincentivaron la inversión en otros sectores productivos, como 
la industria orientada al mercado interno, un fenómeno conocido en la literatura económica bajo el nombre de "enfermedad holandesa". En consecuencia, la economía no desarrolló otros polos de crecimiento que hubieran podido paliar la debilidad de los sectores exportadores en momentos de baja demanda externa.

A partir de la década de los cincuenta, la creciente insatisfacción con los resultados del modelo primario-exportador suscitó diversos esfuerzos de reforma que buscaron estimular el sector industrial interno. A lo largo de tres gobiernos sucesivos (los gobiernos civiles de Manuel Prado, 1956-1962, y Fernando Belaúnde, 1963-1968, y el régimen militar del general Velasco, 1968-1975 ${ }^{8}$ ), Perú fue adoptando tardíamente un modelo de industrialización por sustitución de importaciones (ISI).

El primer intento se inició con la Ley de Promoción Industrial de 1959, una ley liberal que buscaba incentivar la inversión industrial en general (tanto aquella orientada a la satisfacción del mercado interno como la destinada al procesamiento para la exportación) a través de exenciones a las importaciones de maquinaria e insumos y favorecía alianzas entre inversionistas nacionales y extranjeros. ${ }^{9}$ Durante el gobierno de Fernando Belaúnde (1963-1968), se fortalecieron los incentivos a la IsI, pues se reformó el sistema arancelario, elevándose la protección efectiva a las industrias produciendo para el mercado interno, en particular las de bienes de consumo.

El desarrollo industrial fue apoyado simultáneamente por un mayor gasto público y por una expansión rápida del sistema bancario, bajo control extranjero a altura de $62 \%$ de los activos en $1968 .{ }^{10}$ Gran parte de la industria era entonces propiedad de inversionistas extranjeros o de coinversiones con empresarios nacionales: se estima que en 1968, estas empresas producían $33.5 \%$ de los bienes de consumo, $57 \%$ de los bienes intermedios y $44 \%$ de la producción de la industria metalmecánica. ${ }^{11}$
Finalmente, el modelo de sustitución de importaciones peruano se radicalizó con el gobierno militar reformador del general Velasco, el cual realizó una reforma agraria que acabó con la gran propiedad rural, elevó aún más la protección efectiva de las industrias produciendo para el mercado interno, y nacionalizó los intereses extranjeros, creando un sector de empresas públicas que llegó a representar $30 \%$ del PIB. ${ }^{12}$

En la esfera financiera interna, el gobierno controló gran parte de la asignación de recursos, ya sea mediante la banca de fomento, $o$ a través de los bancos comerciales nacionalizados. Para financiar su mayor intervención en la esfera económica, el gobierno prefirió evitar las tensiones sociales adicionales asociadas a una elevación de la presión fiscal: ${ }^{13}$ en el contexto internacional de abundancia de fondos de los setenta, las autoridades recurrieron de manera intensa al endeudamiento externo para financiar grandes proyectos extractivos y productivos.

El endeudamiento externo, que era sobre todo contratado por el sector privado en la década de los sesenta, fue originándose cada vez más en el sector público. El precio de esta elección fue el estallido de una crisis de deuda externa temprana en $1976^{14}$ que marcó el final de las políticas reformistas, pues el país tuvo que recurrir al financiamiento del Fondo Monetario Internacional y adoptar las políticas de ajuste de corte ortodoxo recomendadas por este organismo.

El período relativamente breve que acabamos de presentar, que se inicia en la década de los cincuenta y termina en 1975, constituyó la Edad de Oro de la industrialización sustitutiva en Perú. ${ }^{15}$ Entre 1950 y 1975 el PIB real creció a una tasa promedio anual de $5.4 \%$, mientras la industria manufacturera, excluyendo las ramas procesadoras de recursos primarios, lo hizo a un ritmo promedio de $8.5 \%$ anual. ${ }^{16}$ Durante este período, la economía se modernizó y la industria manufacturera encabezó el proceso de crecimiento, elevándose su importancia en la generación del PIB de $12.8 \%$ 
en $1950-1954$ a $21.4 \%$ en $1966-1975 .{ }^{17}$ A lo largo de estos años, el salario real manufacturero y el empleo en este sector fueron creciendo hasta culminar en 1976. Sin embargo, la industrialización peruana, liderada por un sector de bienes de consumo durable muy dependiente de la tecnología e insumos importados, tuvo un sesgo antiexportador, debido a que se produjo al abrigo de elevadas barreras proteccionistas, escalonadas en función del tipo de bien. ${ }^{18}$ Nunca logró generar las divisas necesarias para cubrir sus requerimientos de importación y de hecho, la composición de las exportaciones siguió dominada por los productos tradicionales primarios e intensivos en recursos naturales, que constituían $84.2 \%$ de las exportaciones en 1961, y $86.8 \%$ del total en $1974 .^{19}$

De esta manera, la industrialización no sólo aumentó la dependencia de la economía en relación con las exportaciones primarias sino que agregó una vulnerabilidad adicional, pues en caso de caída en el valor de estas exportaciones, el nivel de actividad de la industria manufacturera interna se veía inmediatamente afectado por la incapacidad de proveerse de insumos. El proceso de ISI peruano se quedó trunco, pues no alcanzó a avanzar más allá de la producción de bienes de consumo. En 1976 la economía peruana entró en un largo estancamiento que iba a durar hasta inicios de los noventa.

\section{Estancamiento, inflación creciente y una difícil estabilización, 1976-2004}

El período que se abre en 1976 y va hasta nuestros días se puede dividir claramente en dos grandes etapas: la primera, que termina en 1990, corresponde a la larga crisis de la industrialización sustitutiva. Los tres gobiernos que se sucedieron en el poder, el régimen militar del general Francisco Morales Bermúdez y los dos gobiernos democráticos de Fernando Belaúnde y Alan García, aplicaron diferentes modalidades de estabilización de la economía, ortodoxas para los dos primeros, heterodoxa para el último, pero no modificaron fundamentalmente la estructura de la economía peruana (ver cuadro 2). La segunda etapa, que se inicia con el primer gobierno de Alberto Fujimori, corresponde a la adopción de un nuevo modelo económico y a la apertura comercial y financiera del país.

Las políticas económicas, 1976-2004

Entre 1976 y 1985, las autoridades peruanas aplicaron los característicos programas de estabilización promovidos por el FMI. Éstos buscaban equilibrar las cuentas externas y controlar el alza interna de los precios sobre la base de una reducción de la demanda interna considerada excesiva para los ingresos del país. Para alcanzar estos resultados, se preconizaba disminuir el déficit fiscal, cortando los

Cuadro 2

Los regímenes de política económica en el Perú, 1968-2004

\begin{tabular}{|c|c|c|c|c|c|c|}
\hline Período & Presidente & $\begin{array}{l}\text { Carácter del } \\
\text { régimen }\end{array}$ & Tipo de política económica & $\begin{array}{l}\text { Régimen } \\
\text { cambiario }\end{array}$ & $\begin{array}{c}\text { Tasas de } \\
\text { interés }\end{array}$ & $\begin{array}{c}\text { Política } \\
\text { comercial }\end{array}$ \\
\hline 1968-1976 & General Juan Velasco & Autoritario & $\begin{array}{l}\text { Reformista, capitalismo } \\
\text { de estado }\end{array}$ & Fijo & Controladas & Protección \\
\hline $1976-1980$ & General Francisco Morales & Autoritario & Estabilización ortodoxa & Fijo & Controladas & arancelaria \\
\hline $1980-1985$ & Fernando Belaúnde & Democrático & Estabilización ortodoxa & Fijo & Controladas & elevada \\
\hline $1985-1990$ & Alan García & Democrático & $\begin{array}{l}\text { Estabilización heterodoxa, } \\
\text { pol. de precios e ingresos }\end{array}$ & Fijo & Controladas & $\begin{array}{l}\text { Controles } \\
\text { cuantitativos }\end{array}$ \\
\hline $\begin{array}{r}1990-1995 \\
1995-2000\end{array}$ & $\begin{array}{l}\text { Alberto Fujimori } \\
\text { Alberto Fujimori }\end{array}$ & $\begin{array}{l}\text { Autoritario } \\
\text { Autoritario }\end{array}$ & $\begin{array}{l}\text { Consenso de Washington, } \\
\text { Estabilización ortodoxa y } \\
\text { reforma estructural }\end{array}$ & Flexible & Libres & $\begin{array}{c}\text { Apertura } \\
y\end{array}$ \\
\hline $\begin{array}{l}2000-2001 \\
2001-\end{array}$ & $\begin{array}{l}\text { Valentín Paniagua (transición) } \\
\text { Alejandro Toledo }\end{array}$ & $\begin{array}{l}\text { Democrático } \\
\text { Democrático } \\
\end{array}$ & $\begin{array}{l}\text { Ortodoxa } \\
\text { Ortodoxa } \\
\end{array}$ & $\begin{array}{l}\text { Flexible } \\
\text { Flexible } \\
\end{array}$ & $\begin{array}{l}\text { Libres } \\
\text { Libres } \\
\end{array}$ & $\begin{array}{c}\text { aranceles } \\
\text { bajos }\end{array}$ \\
\hline
\end{tabular}


gastos públicos y elevando los ingresos, en particular a través del ajuste de las tarifas de los bienes producidos por el Estado o las empresas públicas, recortar el poder de compra de los asalariados y devaluar el tipo de cambio. A estos esfuerzos de estabilización y a la recesión que los acompañaba sucedieron intentos de reactivación económica encabezados por el gasto público que fueron de corta duración, pues generaban inmediatamente un déficit comercial insostenible.

Las medidas tomadas por estos dos gobiernos para corregir las deficiencias del modelo de industrialización sustitutiva no tuvieron un impacto suficiente para hacerlo viable. Tampoco se tomaron medidas liberalizadoras de gran alcance. Un primer intento de corrección se hizo entre 1977 y 1980 , con el fomento a las exportaciones "no-tradicionales" (productos manufactureros y procesados no primarios), que fue relativamente exitoso; con el cambio de gobierno en 1980, se inició un proceso de apertura comercial, pronto interrumpido en 1982-1983, cuando Perú se vio arrastrado en la crisis de la deuda latinoamericana y sufrió el impacto catastrófico del fenómeno natural del Niño. ${ }^{20}$

El período siguiente (1985-1990) es marcado por un cambio radical de estrategia estabilizadora. El nuevo gobierno decidió combatir el cuadro de inflación alta y recesión que padecía el país; se aplicaron para ello, al igual que en Brasil y Argentina, políticas "heterodoxas" que buscaban estabilizar y a la vez reactivar la economía.

La política macroeconómica partía del diagnóstico según el cual la inflación no reflejaba un exceso de demanda sino que se originaba en las alzas de costos -en especial del tipo de cambio y de los combustibles- fomentadas por las políticas ortodoxas de estabilización. La política de precios e ingresos, central en este esquema, consistió en un reajuste inicial que elevó los ingresos salariales con el objetivo de combatir la recesión, estableció una nueva estructura de precios, y, en el sector externo, fijó tipos de cambios múlti- ples; todos los precios quedaron congelados, y las futuras modificaciones fueron sujetas a autorización gubernamental.

Para simplificar las transacciones y a la vez crear expectativas positivas, se decidió la creación de una nueva moneda, el inti, equivalente a mil antiguos soles. Los depósitos bancarios denominados en dólares, un instrumento financiero muy popular en el período anterior, pues permitía proteger el poder de compra frente a una inflación creciente, fueron congelados. Las importaciones quedaron sujetas a sobretasas y controles cuantitativos; el sistema arancelario se complejizó: a finales del período (1990) existían 56 tasas arancelarias diferentes y catorce sobretasas. ${ }^{21}$ Asimismo, se decidió limitar el pago de intereses sobre la deuda externa a una fracción del valor exportado, lo que implicó para el país una prolongada exclusión de los mercados financieros internacionales.

Si bien tuvo inicialmente resultados favorables, expresados en una disminución de la inflación y una dinamización del crecimiento del PIB, este programa tampoco resolvió los problemas de la economía peruana, sino que los agravó. El descontrol del déficit fiscal, asociado a una reforzada aceleración inflacionaria que derivó en hiperinflación, la profundización del déficit comercial y un contexto internacional caracterizado por la ausencia total de préstamos voluntarios hacia el país pronto desencadenaron una crisis que amenazó seriamente su estabilidad política y social.

El gobierno del ingeniero Alberto Fujimori se inició en 1990 en el contexto de una pérdida generalizada de control sobre las variables económicas e inclusive sobre una porción de su territorio de parte del Estado. El programa de estabilización se combinó desde el inicio con reformas estructurales introducidas como "terapia de choque". Perú, que se encontraba hasta 1991 relativamente rezagado en relación con el promedio regional de avances en las reformas estructurales liberalizadoras (con un valor del índice sintético de 0.399 comparado con el valor regional de 0.455 ), se coloca desde 1993 en el grupo de 
países donde estas reformas se encuentran más avanzadas. ${ }^{22}$

En agosto de 1990 se liberalizaron todos los precios y se estableció un régimen de cambio flotante. La oferta de dinero se utilizó como "ancla" nominal para estabilizar los precios. La pérdida de poder de compra del inti, símbolo del régimen anterior, era tal que se decidió su remplazo por el nuevo sol, que equivalía a un millón de intis. El sistema arancelario fue reformado y simplificado rápidamente. En 1993 los aranceles promedio alcanzaban $15 \%, 11 \%$ y $12 \%$ para los bienes de consumo, los bienes intermedios y los bienes de capital respectivamente, en contraste con niveles de $73 \%, 71 \%$ y $68 \%$ en $1985 .^{23}$

En el ámbito fiscal se estableció un "comité de caja” encargado de ajustar los gastos del Estado a sus ingresos. El gobierno fomentó el retiro voluntario de servidores públicos, elevó ciertos impuestos (combustibles, impuestos temporales a la riqueza) y en 1996 logró reabsorber el déficit público, a través de una contracción del gasto y una elevación de la recaudación de impuestos, obtenida gracias a un notable fortalecimiento de la administración fiscal. Se emprendió un amplio programa de privatizaciones, realizándose alrededor de doscientas ventas de empresas públicas entre 1990 y $1999,{ }^{24}$ que incluyeron, entre otros, bancos comerciales, empresas petroleras, mineras y siderúrgicas así como la aerolínea nacional. Perú restableció relaciones con el FMI y a par- tir de 1993 recibió el apoyo de este organismo a su programa económico; en 1996-1997, el país reestructuró su deuda con sus acreedores externos, comerciales, gobiernos miembros del club de París, Federación Rusa y otros. ${ }^{25}$

En el ámbito financiero, las autoridades monetarias emprendieron la remonetización de la economía a través de la compra de las divisas, esencialmente dólares estadounidenses, que circulaban ampliamente en el país, reestructuraron el sistema bancario y fomentaron el desarrollo del mercado de valores. La legalización de las cuentas bancarias y de los pagos en dólares fue necesaria para la recuperación del sistema durante toda la década de los noventa y es solamente recientemente que el gobierno de Alejandro Toledo ha procurado disminuir su papel.

\section{Inestabilidad macroeconómica y estabilización: 1976-2004}

Una elevada inflación, crónicos déficit fiscales y comerciales, una excesiva carga de deuda externa así como un crecimiento económico escaso y volátil caracterizaron la mayoría del período considerado en este artículo. La alta inflación es tal vez el elemento más visible de la larga postración de la economía peruana. La evolución de la tasa de crecimiento mensual anualizada de los precios al consumidor, expresada en términos logarítmicos (gráfica 2), permite observar la paulatina aceleración inflacionaria: inferior a $10 \%$ antes de 1973, el

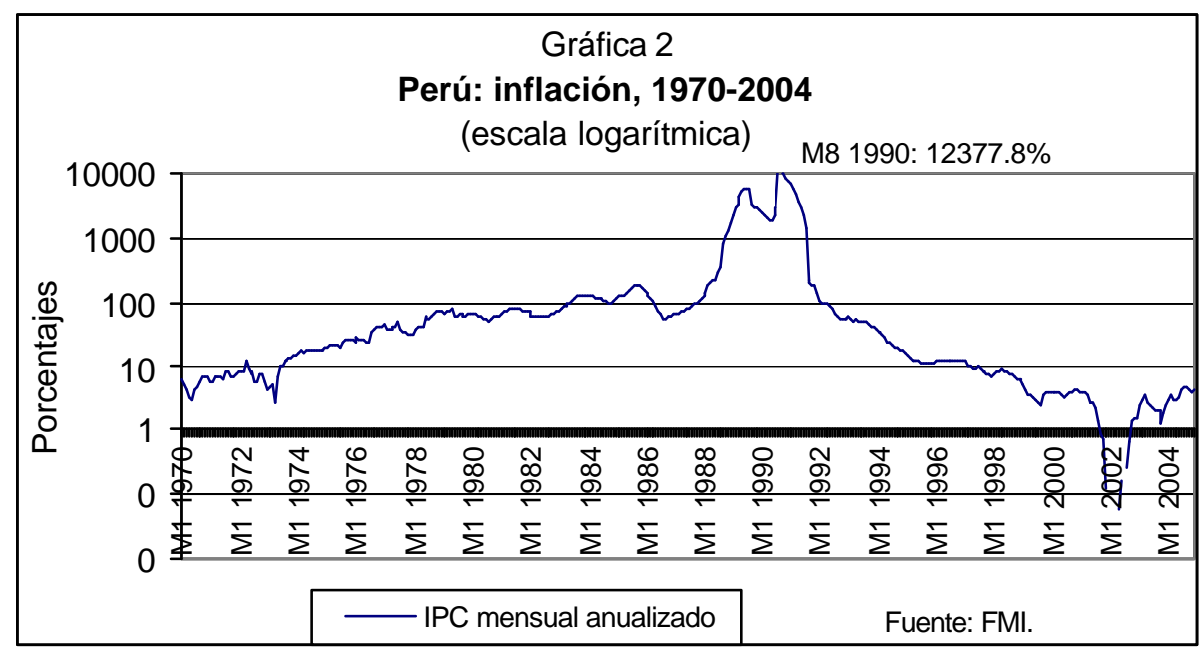




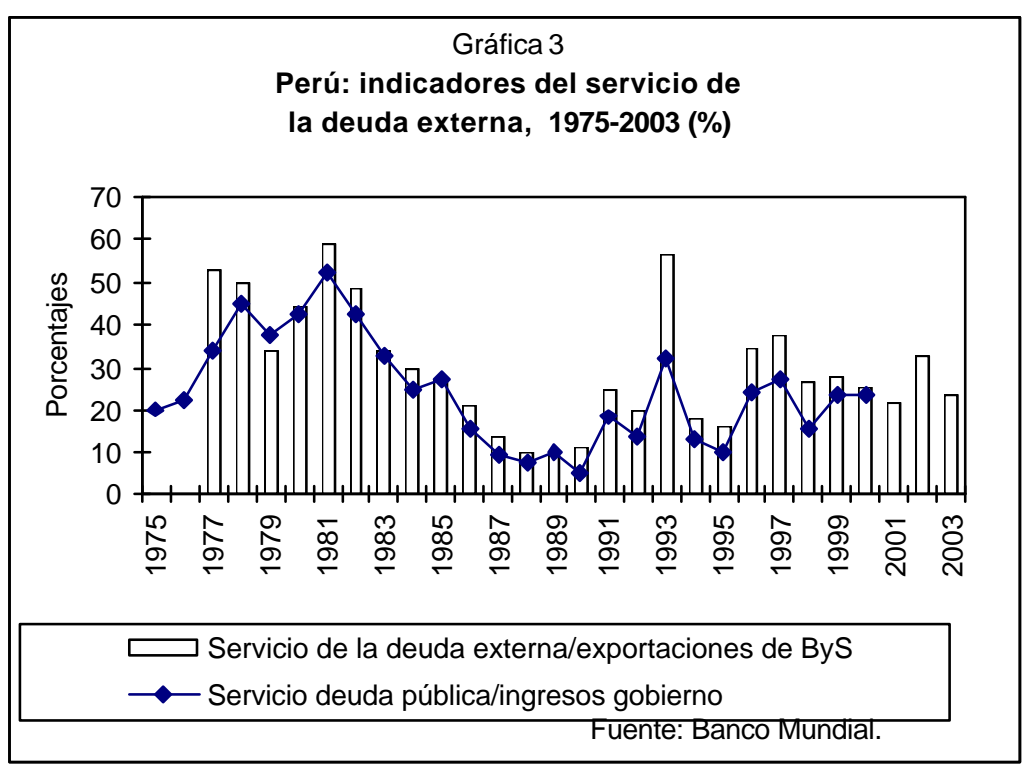

ritmo de crecimiento de los precios se acelera en la segunda mitad de la década, al igual que en la mayoría de las economías en desarrollo y en parte debido al impacto de los desórdenes monetarios internacionales. El fracaso de los programas de estabilización ortodoxos de la primera mitad de los ochenta y choques exógenos llevan a "picos" inflacionarios que no sobrepasan un ritmo anualizado de $200 \%$. El fracaso de la política heterodoxa del gobierno de Alan García desencadena el proceso hiperinflacionario que culmina en un ritmo anualizado de $12377 \%$ en agosto de 1990, cuando el nuevo gobierno de Alberto Fujimori libera los precios. En contraste con otras experiencias hiperinflacionarias, la posterior disminución del ritmo de incremento de los precios no fue abrupta sino lenta, y es solo desde inicios de 1997 que la inflación se situó por debajo del $10 \%$ anual para ubicarse en niveles bajos, cercanos al $2 \%$ anual en los primeros años de 2000.

En la década de los noventa, la estabilización del nivel de precios ha ido asociada a ajustes notables en dos precios relativos clave para la economía, con fuertes implicaciones para el comercio exterior y para la demanda interna: el tipo de cambio real ha experimentado una fuerte apreciación mientras el poder de compra de los salarios caía. Al disminuir el costo de los bienes importados y aumentar su ofer-

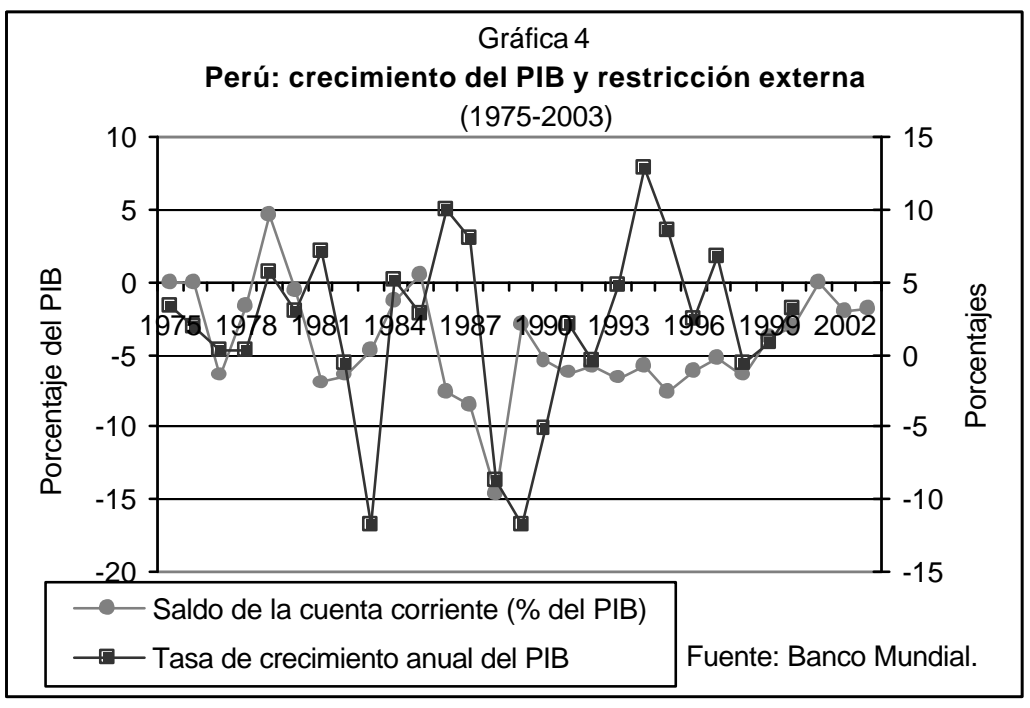


ta, la apreciación del tipo de cambio real y la liberalización comercial han desempeñado un papel central en el proceso de desinflación.

Sin embargo, la apreciación cambiaria no ha sido pasajera sino perdurable, y llevó a los observadores de la economía peruana a debatir acerca del carácter estructural de este cambio. En 1995 el tipo de cambio real representaba $49.8 \%$ del nivel que mostraba en $1975^{26}$ y permaneció estable hasta 1998, presentándose una depreciación a partir de 1999, la que de ninguna manera ha sido suficiente para regresar a los niveles "históricos" del tipo de cambio de la moneda peruana. ${ }^{27}$ Como lo veremos, esta trayectoria del tipo de cambio real del sol peruano ha sido posible por la abundancia relativa de fondos externos prevaleciente en el período de estabilización, y por otro lado, ha afectado negativamente el desempeño de las exportaciones, en especial las no-primarias, al elevar relativamente los costos de los bienes producidos en el país.

El salario real es el segundo precio relativo clave de la economía que ha sufrido cambios drásticos durante la hiperinflación y la posterior estabilización. En efecto, el impacto de la alta inflación ha sido dramático para la mayoría de los asalariados, pues a pesar del carácter prolongado de este proceso, la economía peruana nunca desarrolló mecanismos de indización suficientes para frenar la caída de este tipo de ingresos. En consecuencia, el deterio- ro del poder adquisitivo de los salarios ha sido impresionante: en 1994 el índice de salario real manufacturero equivalía a $67 \%$ del salario real de 1989 , a $33 \%$ del de 1987 y sólo a $23 \%$ de su nivel máximo alcanzado en $1976 .{ }^{28}$ La recuperación posterior de los ingresos salariales ha sido nula, como lo muestra el índice de remuneraciones promedias reales: para un nivel inicial de 100 en 1995, éste alcanzaba valores de 90.6 en 2001 y de 95.2 en $2004 .^{29}$

Los déficit fiscales crónicos y la restricción externa al crecimiento que se observan en el período de crisis de la IsI no pueden entenderse a cabalidad sin mencionar previamente el sobreendeudamiento externo que cargan la economía y el gobierno de Perú desde mediados de los setenta (gráfica 3).

La carga excesiva de la deuda se puede apreciar tanto en su relación con el valor exportado como en la proporción de los ingresos fiscales que representa. Calculado en porcentaje de las exportaciones de bienes y servicios, el servicio de la deuda externa era considerable, pues representaba alrededor de 50\% de dichas exportaciones en 1977-1978, proporción que subió a 59\% en 1981, después del alza de las tasas de interés externas. En tanto porcentaje de los ingresos del gobierno, el peso del servicio de la deuda pública, en su mayor parte externa, no era menos agobiante: superaba $52 \%$ de los ingresos en 1981. Como lo hemos visto, el servicio se realizó de manera parcial

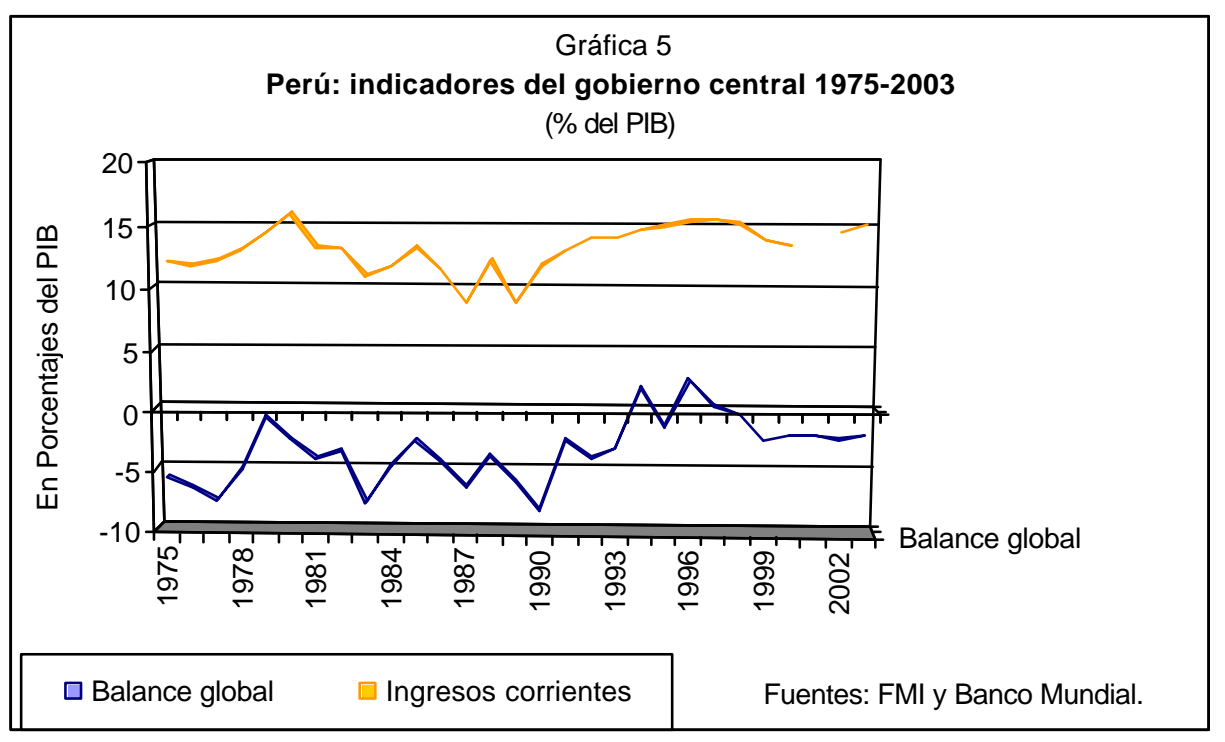


entre 1985 y 1990, y cuando se reanudó alcanzó otra vez niveles elevados (56\% del valor exportado y $32 \%$ de los ingresos del gobierno en 1993).

La vigencia de la restricción externa al crecimiento económico aparece en la gráfica 4 : la economía se hallaba en la incapacidad de generar las divisas requeridas simultáneamente por el crecimiento y por el servicio de la deuda externa. A lo largo del período de crisis de la ISI, todo intento de reactivación económica a través de un aumento del gasto fiscal real se traducía en un empeoramiento del déficit en cuenta corriente, ${ }^{30}$ el que era suprimido posteriormente con políticas de contracción de la demanda interna, creando un fenómeno de stop and go en el crecimiento económico.

De hecho, entre 1975 y 1993, aún cuando se realizaron esfuerzos de recorte de los gastos reales, ningún presupuesto público ha sido equilibrado, debido al peso del gasto financiero asociado al servicio de la deuda pública. Es más, como producto de la erosión del valor real de la recaudación atribuible a la aceleración inflacionaria, la década de los ochenta ha sido marcada por un continuo deterioro de los ingresos corrientes del gobierno, que cayeron en un bajísimo nivel de $8.6 \%$ del PIB en 1987 y $1989^{31}$ (gráfica 5). En 1983 (año marcado por las consecuencias devastadoras del fenómeno del Niño) y en 1990 (año en el cual culmina la hiperinflación) el déficit del gobierno central alcanzó respectivamente 7.44 y $8.11 \%$ del PIB.

Ahora bien, en los años noventa la estabilización del nivel de precios no ha implicado una inmediata corrección en las trayectorias de estas tres variables. No se dio una rápida reducción del déficit fiscal, pues es solamente en 1994 y 1996 que el balance se tornó positivo ( $2.17 \%$ y $2.78 \%$ del PIB, respectivamente) sobre la base de políticas más contractivas del gasto real. En los últimos años, el déficit ha reaparecido a un nivel moderado, porque se establece en un nivel anual promedio inferior a $2 \%$ del PIB. Asimismo, la estabilización y el cambio de modelo económico, lejos de resolver el problema de la cuenta corriente, ahondaron durante varios años el déficit. Como lo veremos en la sección siguiente, este comportamiento obedeció a las excepcionales entradas de fondos que se registraron en estos años.

Esta tendencia culminó en 1995, con un déficit en cuenta corriente de $7.7 \%$ del PIB, que se redujo en años posteriores. Finalmente, fue sólo después de la renegociación que el peso del servicio de la deuda se ha reducido, sin por ello dejar de ser elevado: de 1997 a 2003, ha oscilado entre $24 \%$ y $37 \%$ del valor exportado y se estableció en un promedio superior a $20 \%$ de los ingresos del gobierno (ver gráfica 5). En fin, el comportamiento de estas tres variables -el balance global del gobierno, la cuenta corriente y el peso del servicio de la deudaparece haber mejorado simultáneamente a fi-

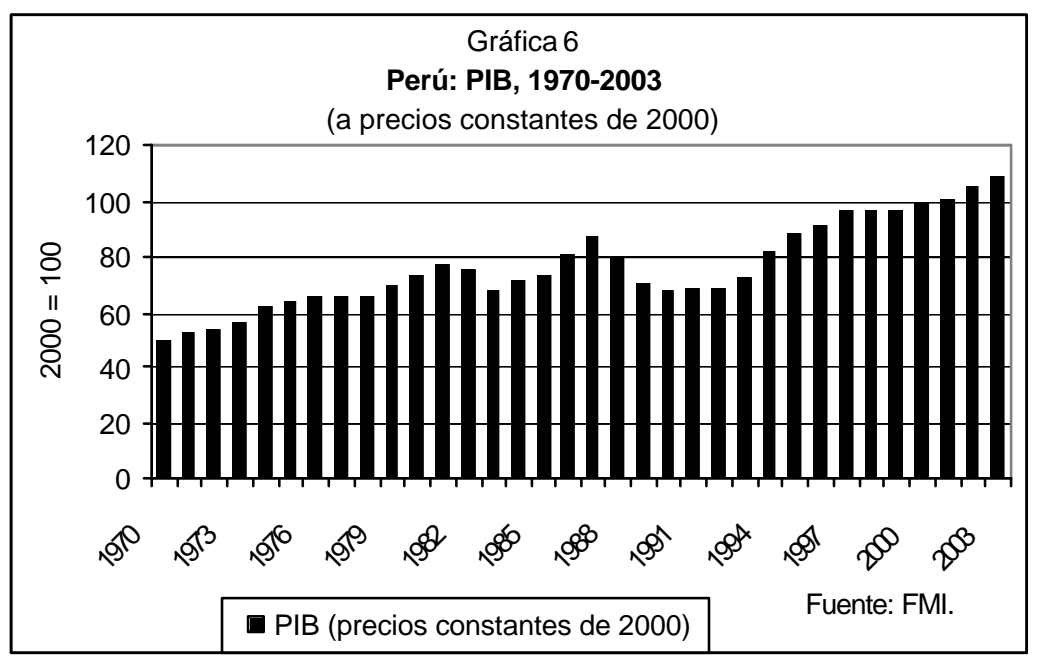


nales de la década de los noventa, es decir cuando la desinflación ya se había producido. La reducción en el servicio de la deuda podría haber desempeñado un papel esencial en estos desarrollos, y a partir del año 2000, la disminución de las tasas de interés internacionales y, más recientemente, el alza de los precios de exportación de las materias primas peruanas han permitido profundizar esta mejoría.

En suma, el carácter agobiante del servicio de la deuda combinado con las deficiencias estructurales del modelo de iss impidieron todo crecimiento económico duradero e incluso un mínimo grado de estabilidad macroeconómica hasta inicios de los noventa. Las políticas de estabilización y cambio estructural de esta década permitieron a Perú salir de la alta inflación y alcanzar estabilidad en las principales variables macroeconómicas, pero con costos asociados expresados en apreciación cambiaria y en pérdida de poder adquisitivo de los salarios.

Los añejos desequilibrios de la cuenta corriente y del balance fiscal no se resolvieron tan rápido y el servicio de la deuda externa, aún cuando es más sostenible que en la década de los ochenta, sigue absorbiendo recursos importantes. En la sección siguiente analizaremos algunos aspectos centrales del cambio de modelo económico en Perú.

\section{Crecimiento y sector externo, 1975- 2004}

El período de treinta años que se analiza en este texto ha sido caracterizado por un muy modesto crecimiento económico: la crisis del modelo de isi y la postergación de las reformas que éste requería tuvieron como consecuencia un prolongado estancamiento del PIB, observable en la gráfica 6 . A lo largo de más de quince años, el PIB real de la economía peruana (calculado a precios de 2000) apenas creció, pues pasó de un nivel de 66 en 1976-1978 a 69 en 19911992 , debido a que las ganancias de los períodos de reactivación fueron borrados por las recesiones que les siguieron. Simultáneamente, el PIB PC expresado en dólares corrientes pasaba de 1080 (1976) a 1030 (1991), ${ }^{32}$ expresado en moneda nacional (pesos constantes de 2000), su caída es mucho más estrepitosa (gráfica 7): 3691 soles en 1992 contra 5542 en 1975. En contraste con la "década perdida" de América Latina, Perú experimentó más bien tres lustros de estancamiento y vaivenes macroeconómicos extremos.

Es solamente a partir de los cambios estructurales de inicios de los noventa que la economía peruana reanuda un proceso de crecimiento económico relativamente dinámico, basado inicialmente en la expansión del sector primario, en especial el extractivo, y en la construcción. Sin embargo, recae en la rece-

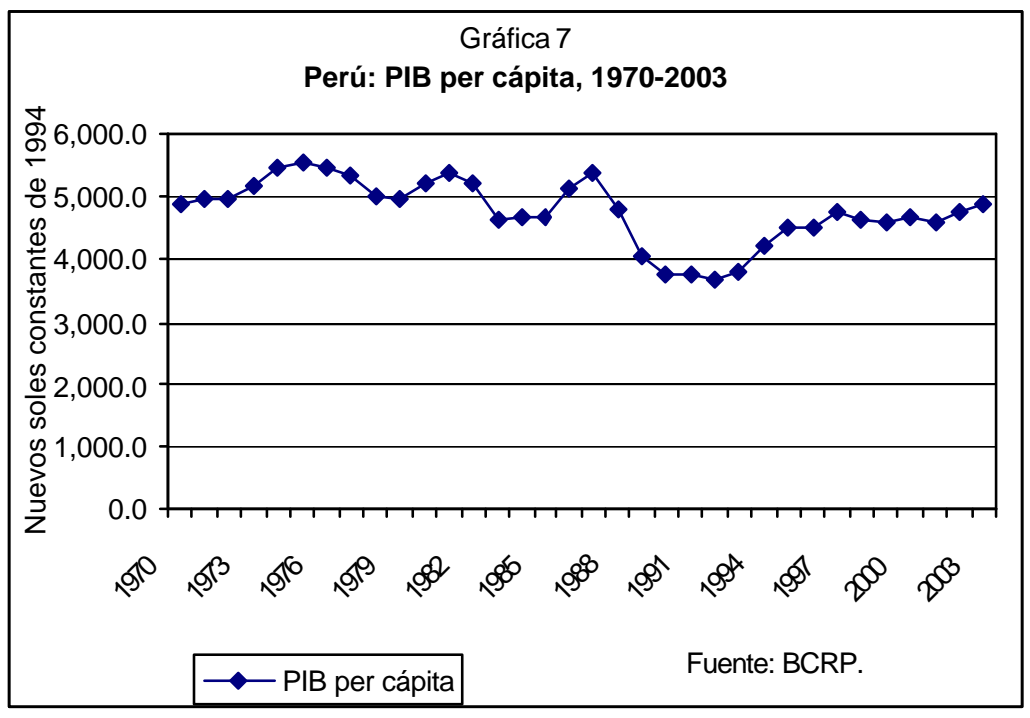




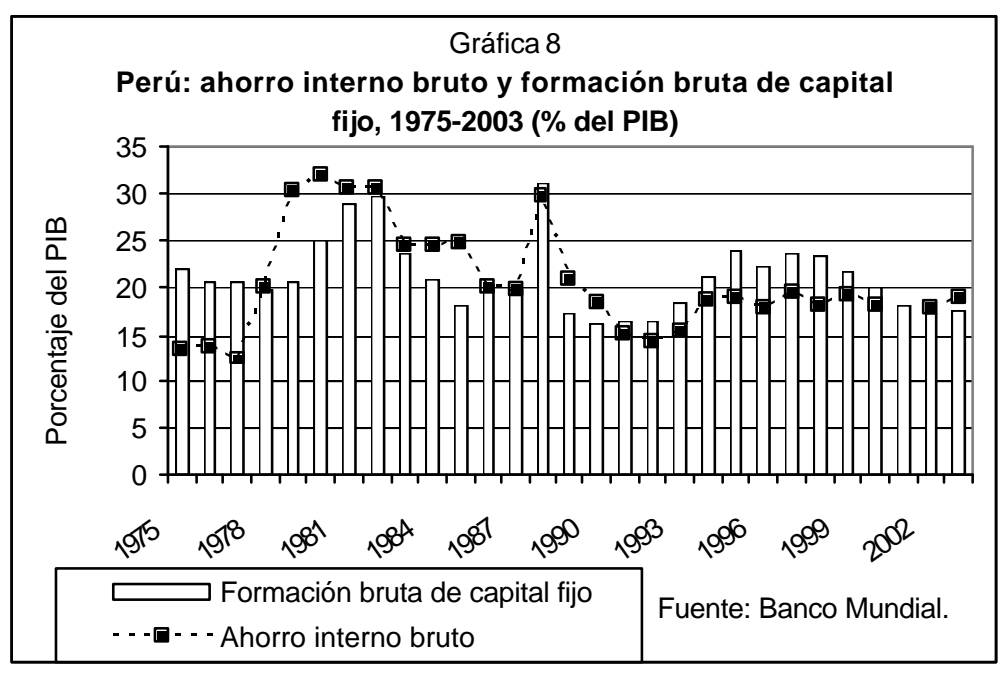

sión entre 1997 y 2000, tanto como producto de choques provenientes del ámbito internacional - la crisis asiática y la posterior caída en la demanda de productos primarios- como en razón de dificultades internas relacionadas con la inestabilidad política y los escándalos de corrupción que acompañaron el final del gobierno autoritario de Alberto Fujimori, su abandono del cargo y el establecimiento de un gobierno de transición.

Desde el año 2001, la economía ha ido creciendo, con un primer impulso dado por factores de orden financiero: en una economía dolarizada, la disminución de las tasas de interés estadounidenses permitió la baja de las tasas internas y la reactivación de la demanda urbana. En segundo lugar, la reactivación se sustentó en medidas que alentaron el sector de la construcción interna, así como en las exportaciones de bienes manufacturados (textiles principalmente) hacia Estados Unidos. ${ }^{33}$ Por último, Perú se vio favorecido desde 2003 por la fuerte demanda asiática de productos primarios, que ha permitido dinamizar las exportaciones y mejorar su balanza comercial. Al final del período, el índice del PIB expresado en soles constantes alcanzaba un nivel de 109 puntos, una muy modesta progresión a lo largo del período completo, pero el PIB per cápita en moneda nacional -4 868 soles en 2003 era todavía más bajo que el registrado en 1975: el empobrecimiento absoluto de Perú no habría sido revertido del todo, en contraste con lo que sugieren las cifras expresadas en dóla-

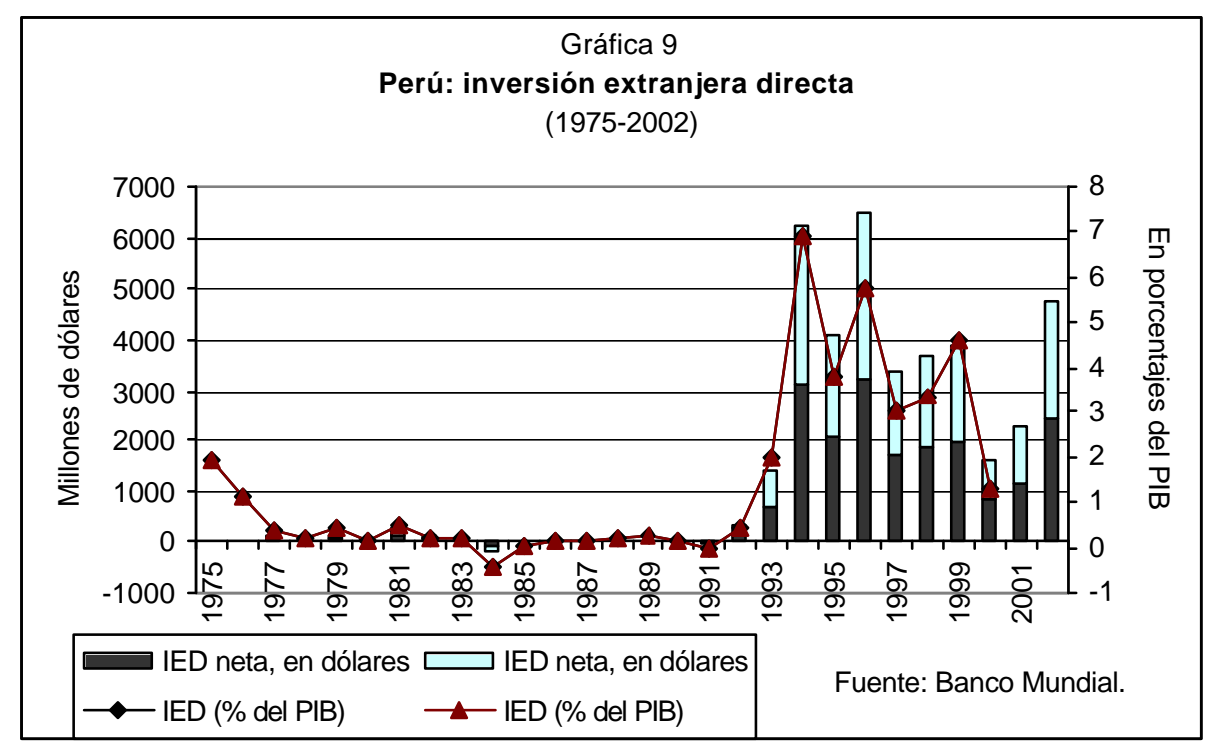




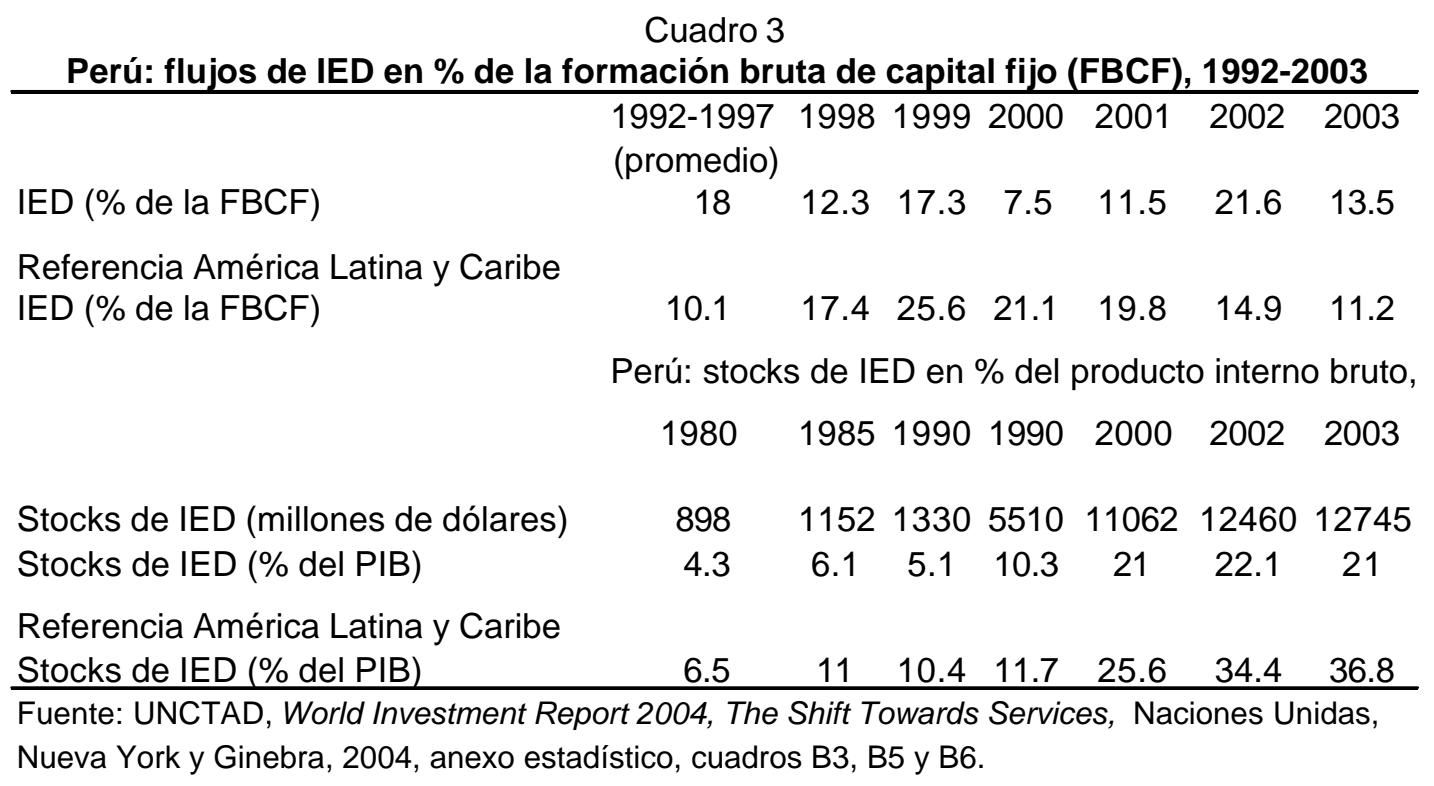

res, que incluyen la notable apreciación de la moneda peruana.

Aún considerando su desempeño de la última década, permanecen fuertes restricciones estructurales a un crecimiento dinámico de la economía peruana. La gráfica 8 , que muestra las razones de ahorro e inversión en relación con el PIB, permite observar que las reformas de los noventa rompieron con la elevada volatilidad experimentada por ambos indicadores en el período 1978-1992, estableciendo un patrón más estable. Sin embargo, la modesta alza en la razón de formación bruta de capital fijo (FBCF) que se produjo entre 1994 y 1999 (22.8\% del PIB en promedio) no se sostuvo en los primeros años de la década siguiente, ubicándose entre $2002-2003$ en $17.5 \%$. Si no se revierte rápidamente, este bajo nivel de inversión plantea claramente dudas acerca del carácter sostenible de un crecimiento dinámico de la economía.

Ahora bien, cabe también subrayar que el mayor nivel de FBCF ha sido financiado a partir de 1992 hasta 2000 sobre la base de mayores entradas de capitales externos. Como lo muestra la gráfica 8 , el ahorro interno no se

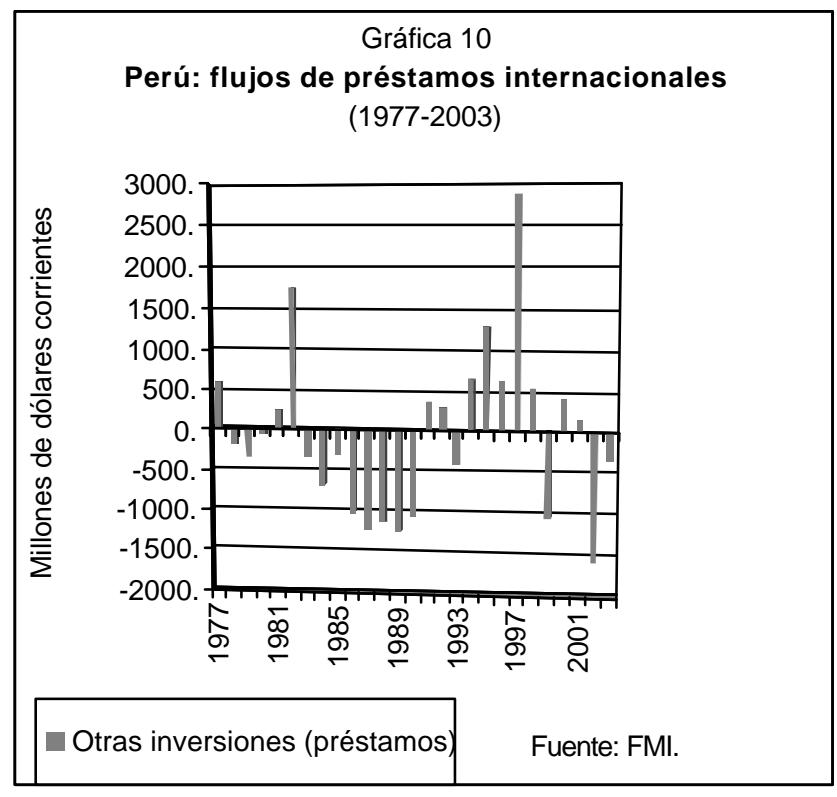


Cuadro 4

Perú: evolución del PIB por sectores, 1992-2004 (índice 1994=100)

\begin{tabular}{|c|c|c|c|c|c|c|c|}
\hline \multirow[t]{2}{*}{ Año } & \multirow[t]{2}{*}{ Agropecuario } & \multirow[t]{2}{*}{ Minería } & \multicolumn{2}{|c|}{ Industria } & \multirow[t]{2}{*}{ Construcción } & \multirow[t]{2}{*}{ Comercio } & \multirow[t]{2}{*}{ PIB } \\
\hline & & & $\begin{array}{c}\text { Procesadora } \\
\text { de rec. primarios }\end{array}$ & No primaria & & & \\
\hline 1992 & 81,0 & 80,1 & 80,4 & 83,7 & 62,3 & 83,8 & 84,6 \\
\hline 1993 & 88,3 & 90,1 & 86,6 & 85,5 & 73,5 & 86,3 & 88,6 \\
\hline 1994 & 100,0 & 100,0 & 100,0 & 100,0 & 100,0 & 100,0 & 100,0 \\
\hline 1995 & 109,5 & 107,5 & 96,4 & 108,2 & 117,4 & 111,1 & 108,6 \\
\hline 1996 & 115,3 & 112,8 & 100,0 & 109,2 & 114,7 & 112,1 & 111,3 \\
\hline 1997 & 121,5 & 129,7 & 101,9 & 115,9 & 131,8 & 120,8 & 118,9 \\
\hline 1998 & 122,1 & 132,5 & 91,9 & 113,8 & 132,6 & 117,1 & 118,1 \\
\hline 1999 & 134,5 & 153,7 & 106,5 & 108,5 & 118,6 & 115,9 & 119,1 \\
\hline 2000 & 143,3 & 159,7 & 116,2 & 113,8 & 110,9 & 120,4 & 122,6 \\
\hline 2001 & 144,2 & 181,5 & 114,2 & 115,3 & 103,7 & 121,4 & 122,9 \\
\hline 2002 & 152,9 & 203,8 & 114,2 & 121,3 & 111,9 & 126,6 & 128,8 \\
\hline 2003 & 156,5 & 219,5 & 112,1 & 125,2 & 116,6 & 131,5 & 133,7 \\
\hline 2004 & 154,8 & 230,9 & 117,4 & 134,2 & 122,1 & 137,6 & 140,4 \\
\hline
\end{tabular}

Fuente: Banco Central de Reserva del Perú, estadísticas consultadas en línea en http://www.bcrp.gob.pe.

ha elevado en la misma proporción que la inversión, y es la inversión extranjera directa (IED) combinada con préstamos bancarios internacionales que han financiado una fracción importante del esfuerzo de FBCF. En efecto, la IED, insignificante desde inicios de los años setenta tanto en valor como en proporción del PIB, repuntó a partir de las reformas e incluso antes de que Perú hubiera renegociado su deuda externa (gráfica 9): culminó en 1994 y 1996, con flujos netos superiores a 3000 millones de dólares y respectivamente de $6.92 \%$ y $5.78 \%$ del PIB, alcanzando niveles menores en 20002001. En determinados años (1994, 1995 y 1997), el valor de las fusiones y adquisiciones internacionales de empresas alcanzó a representar una parte muy alta de la IED, lo cual muestra que estos flujos tuvieron un importante componente de compras de empresas existentes (vinculado en particular al proceso de privatización de empresas públicas), el que llegó a predominar sobre la inversión en proyectos nuevos (greenfield investment). Considerada en conjunto, la IED constituye una fracción significativa de la FBCF desde 1992 (15\% en promedio para el período 1992-2003), aún cuando su importancia es todavía relativamente menor que para el conjunto de América Latina y el Caribe (cuadro 3).

Los préstamos internacionales (el rubro predominante de las "otras inversiones" en la

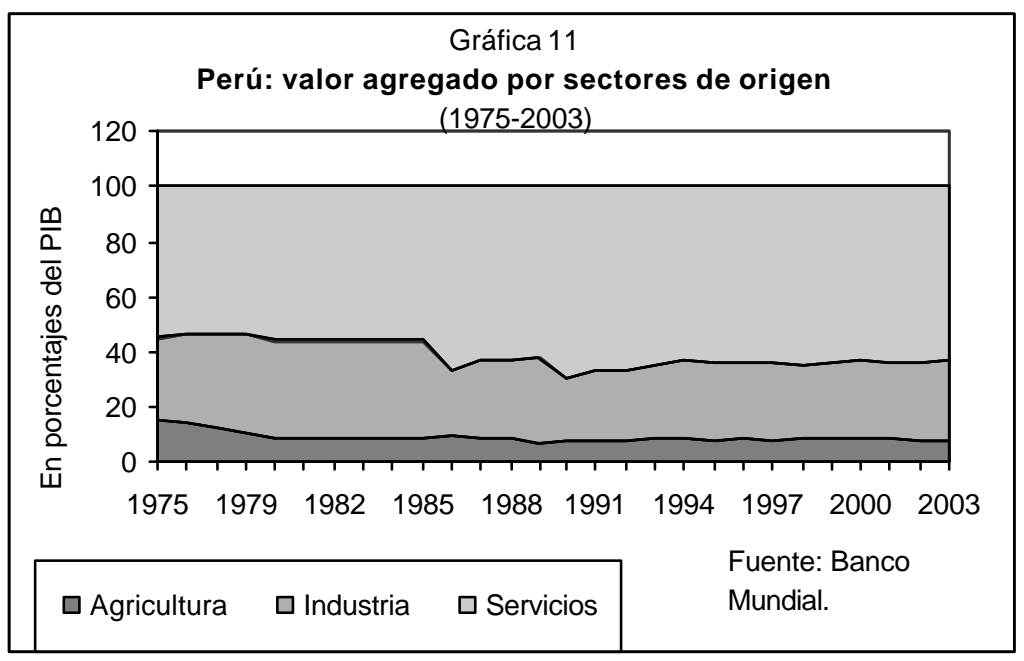


terminología del FMI) fueron por su parte especialmente relevantes entre 1994 y 1997, y culminaron en este último año con entradas de 2880 millones de dólares (gráfica 10); ahora bien, en contraste con la IED, estos flujos no se recuperaron después de las crisis financieras de fines de los noventa-inicios de 2000, y se tornaron mayormente negativos después, cuando Perú, al igual que las demás economías en desarrollo, vuelve a ser exportador neto de fondos en este rubro. En suma, el crecimiento más dinámico de mediados de la década de los noventa, en parte constituido por la recuperación de recesiones previas, se ha fundamentado en entradas récord de capitales provenientes del exterior, que muestran el carácter excepcional del período, ${ }^{34}$ quedando por ver qué nivel de crecimiento se podrá alcanzar en circunstancias más normales de relativa escasez de fondos.

Ahora bien, ¿qué tipo de crecimiento económico ha ido conformándose con las reformas estructurales de la década de los noventa? ¿Cuáles fueron sus límites? Destacaremos en esta sección dos de sus características importantes: por un lado, la desindustrialización de la economía y la creciente ubicación de la población en actividades de servicios "informales" de sobrevivencia, con baja productividad, y por otro lado, el fracaso en generar un mayor nivel relativo de comercio exterior.

El rasgo tal vez más distintivo del crecimiento de la economía peruana después del cambio de modelo económico es que ha sido liderado por los sectores primarios. Como lo muestra el cuadro 4, los sectores agropecuario y minero han crecido a tasas mucho más altas que el resto de la economía. La minería en particular casi triplicó el valor de su producción entre 1992 y 2004. En contraste, las actividades industriales en su conjunto y la construcción quedaron rezagadas, aún cuando aceleraron algo su crecimiento en los últimos años. Considerada en su conjunto, la contribución de la industria al PIB disminuyó de $35.15 \%$ en 1985 a $30.3 \%$ en 1989 , estableciéndose en $27.8 \%$ desde 1995 a 2002 (gráfica 11), dándose un repunte en 2003 a $28.6 \%$ del valor agregado de la economía, tal vez atribuible a las mayores exportaciones textiles hacia Estados Unidos.

Simultáneamente, se daba un cambio importante en la composición del valor agregado manufacturero, que permite hablar de un verdadero retroceso en el proceso de industrialización. En efecto, se ha producido una contracción de las actividades productoras de bienes de consumo durable y maquinaria, de mayor valor agregado, que pasan de $13 \%$ del valor agregado manufacturero en 1987 a $4.9 \%$ en 1994, elevándose en contraste la participación de las industrias productoras de bienes intermedios (38.7\% a $46.3 \%$ del total) que aprovechan la disponibilidad de procesados primarios (de origen minero en particular). ${ }^{35}$ La contracción manufacturera, aunada a la menor importancia relativa del sector agrícola

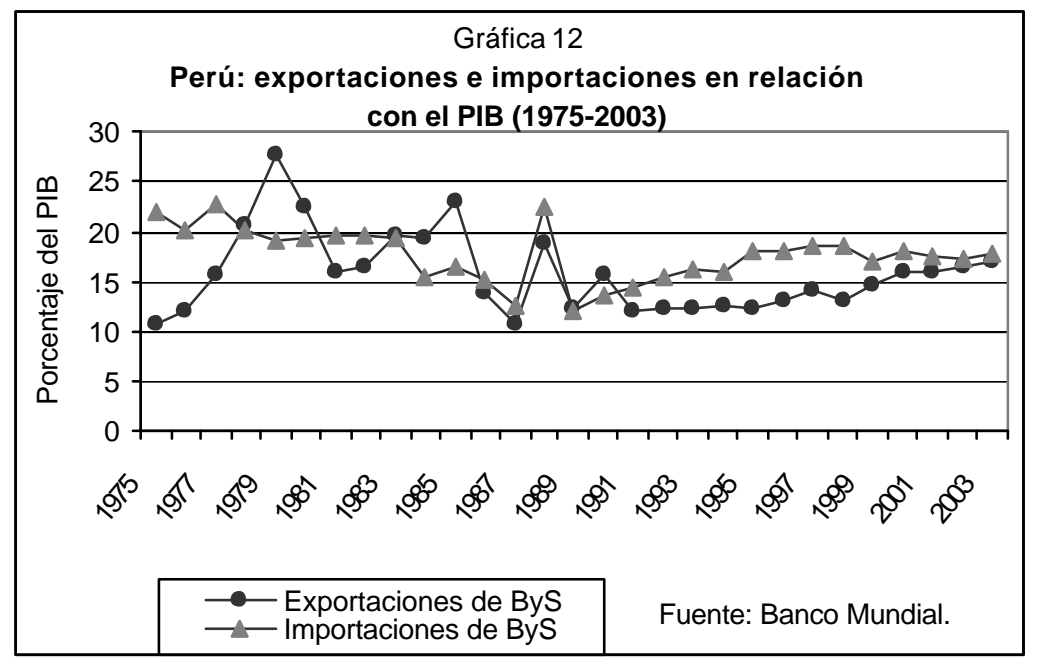


(menos de 8\% del PIB en 2003) dejó el sector servicios como el mayor generador de valor agregado y de empleo en la economía (respectivamente, $63.6 \%$ y $74.5 \%$ en 2003 ). Ahora bien, como lo muestra la discrepancia entre el valor agregado y la proporción del empleo absorbido por este sector, está constituido en buena parte por actividades de comercialización de muy bajo valor agregado, que permiten a la población sobrevivir a través de un subempleo autogenerado y paliar los efectos de la insuficiencia de oferta de trabajo: el desempleo urbano en la capital, que afectaba $8.2 \%$ de la población activa en 1995 se elevaba en 2003 a $9.4 \% .36$

El segundo límite notorio del nuevo modelo económico adoptado por Perú reside en que no ha logrado elevar de manera sensible la importancia de las exportaciones, lo que hace dudar de su capacidad para transformarse en un poderoso motor de crecimiento. Perú es una de las pocas economías en desarrollo latinoamericanas que no han visto elevarse su grado de apertura económica, medido por el coeficiente de exportaciones e importaciones en relación con el PIB. La razón exportaciones/ PIB ha ido creciendo paulatinamente desde las reformas, pero sigue siendo inferior a su nivel promedio de fines de los setenta-inicios de los ochenta: con un nivel de $17 \%$ del PIB en 2003, era una de las más bajas de América Latina, de por sí un continente de economías poco abiertas.

¿Cómo explicar este pobre desempeño comercial? Una razón inmediata al bajo desempeño a la exportación de Perú se puede relacionar con la fuerte apreciación que experimentó la moneda peruana en los noven-

Cuadro 5

Perú: composición del comercio de bienes (1970-2002)

\begin{tabular}{|c|c|c|c|c|c|c|c|c|c|c|}
\hline & \multicolumn{2}{|c|}{1970} & \multicolumn{2}{|c|}{1980} & \multicolumn{2}{|l|}{1990} & \multicolumn{2}{|c|}{2000} & \multicolumn{2}{|l|}{2002} \\
\hline & Valor & $\%$ & Valor & $\%$ & Valor & $\%$ & Valor & $\%$ & Valor & $\%$ \\
\hline \multicolumn{11}{|l|}{ Exportaciones } \\
\hline Bienes primarios & 317,990 & 30.4 & $1,448,542$ & 44.4 & 953,323 & 28.8 & $1,475,205$ & 25.8 & $1,898,920$ & 31.5 \\
\hline Agrícolas & 112,248 & 10.7 & 276,626 & 8.5 & 247,321 & 7.5 & 565,651 & 9.9 & 637,512 & 10.6 \\
\hline Mineros & 199,037 & 19.1 & 619,467 & 19.0 & 687,326 & 20.7 & 782,483 & 13.7 & $1,099,033$ & 18.2 \\
\hline Energéticos & 6,706 & 0.6 & 552,449 & 16.9 & 18,676 & 0.6 & 127,071 & 2.2 & 162,375 & 2.7 \\
\hline Bienes industrializados & 725,356 & 69.5 & $1,812,752$ & 55.5 & $2,358,896$ & 71.2 & $4,244,052$ & 74.2 & $4,121,424$ & 68.4 \\
\hline Tradicionales & 409,211 & 39.2 & 697,107 & 21.3 & $1,003,263$ & 30.3 & $2,137,886$ & 37.4 & $2,196,613$ & 36.5 \\
\hline Alimentos, bebidas y tabaco & 402,773 & 38.6 & 309,725 & 9.5 & 515,028 & 15.5 & $1,216,537$ & 21.3 & $1,187,232$ & 19.7 \\
\hline Otros tradicionales & 6,438 & 0.6 & 387,381 & 11.9 & 488,235 & 14.7 & 921,349 & 16.1 & $1,009,381$ & 16.8 \\
\hline Con elevadas economías de escala & 314,116 & 30.1 & $1,050,568$ & 32.2 & $1,318,028$ & 39.8 & $1,989,112$ & 34.8 & $1,803,241$ & 29.9 \\
\hline Duraderos & 23 & 0.0 & 21,147 & 0.6 & 6,692 & 0.2 & 14,800 & 0.3 & 31,772 & 0.5 \\
\hline Difusores de progreso técnico & 2,005 & 0.2 & 43,931 & 1.3 & 30,913 & 0.9 & 102,254 & 1.8 & 89,798 & 1.5 \\
\hline Otros bienes & 1,051 & 0.1 & 4,207 & 0.1 & 532 & 0.0 & 2,588 & 0.0 & 2,648 & 0.0 \\
\hline Total & $1,044,397$ & 100.0 & $3,265,502$ & 100.0 & $3,312,750$ & 100.0 & $5,721,845$ & 100.0 & $6,022,992$ & 100.0 \\
\hline \multicolumn{11}{|l|}{ Importaciones } \\
\hline Bienes primarios & 86,233 & 13.9 & 320,215 & 12.4 & 406,905 & 15.4 & $1,166,070$ & 15.7 & $1,270,859$ & 17.0 \\
\hline Agrícolas & 81,896 & 13.2 & 281,129 & 10.9 & 240,617 & 9.1 & 435,978 & 5.9 & 487,919 & 6.5 \\
\hline Mineros & 2,404 & 0.4 & 15,201 & 0.6 & 6,855 & 0.3 & 14,834 & 0.2 & 18,559 & 0.2 \\
\hline Energéticos & 1,934 & 0.3 & 23,886 & 0.9 & 159,432 & 6.1 & 715,258 & 9.6 & 764,380 & 10.2 \\
\hline Bienes industrializados & 534,989 & 86.0 & $2,234,205$ & 86.8 & $2,226,852$ & 84.5 & $6,248,719$ & 84.3 & $6,221,896$ & 83.0 \\
\hline Tradicionales & 111,896 & 18.0 & 400,196 & 15.6 & 529,491 & 20.1 & $1,354,925$ & 18.3 & $1,497,985$ & 20.0 \\
\hline Alimentos, bebidas y tabaco & 41,794 & 6.7 & 223,017 & 8.7 & 366,325 & 13.9 & 438,339 & 5.9 & 482,052 & 6.4 \\
\hline Otros tradicionales & 70,102 & 11.3 & 177,179 & 6.9 & 163,166 & 6.2 & 916,586 & 12.4 & $1,015,933$ & 13.6 \\
\hline Con elevadas economías de escala & 177,385 & 28.5 & 719,139 & 27.9 & 746,092 & 28.3 & $2,043,529$ & 27.6 & $2,149,616$ & 28.7 \\
\hline Duraderos & 56,765 & 9.1 & 290,014 & 11.3 & 185,802 & 7.1 & 711,773 & 9.6 & 661,932 & 8.8 \\
\hline Difusores de progreso técnico & 188,942 & 30.4 & 824,856 & 32.1 & 765,467 & 29.1 & $2,138,492$ & 28.8 & $1,912,363$ & 25.5 \\
\hline Otros bienes & 521 & 0.1 & 18,928 & 0.7 & 215 & 0.0 & 247 & 0.0 & 243 & 0.0 \\
\hline Total & 621,743 & 100.0 & $2,573,348$ & 100.0 & $2,633,973$ & 100.0 & $7,415,035$ & 100.0 & $7,492,997$ & 100.0 \\
\hline
\end{tabular}

Fuente: CEPAL, sobre la base de cifras oficiales. 


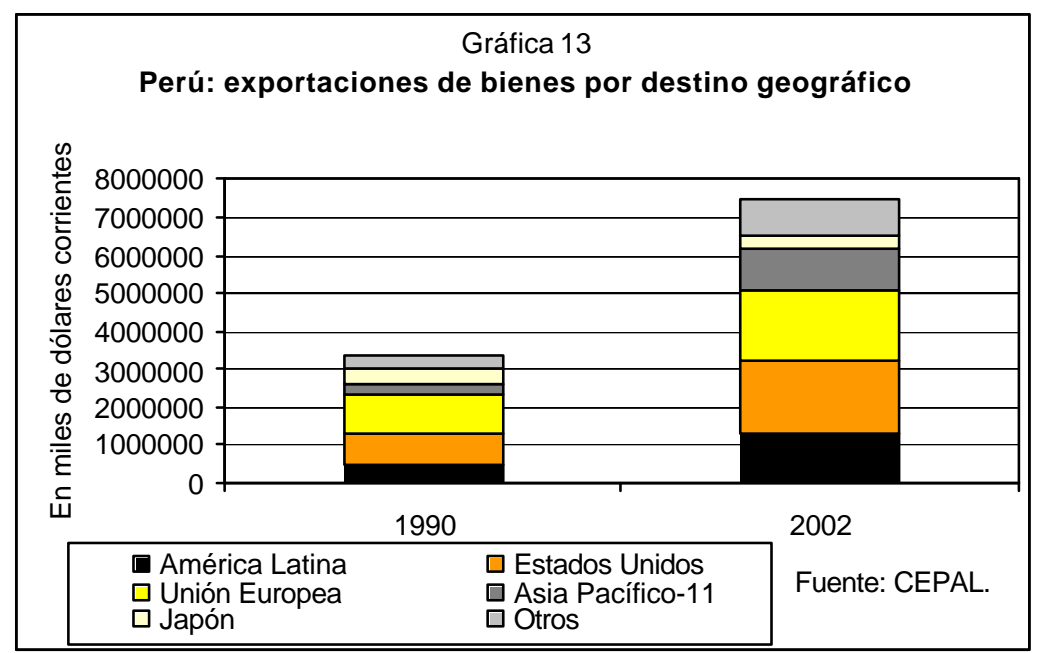

ta: podemos avanzar que ha dificultado la diversificación de las exportaciones hacia bienes industriales que incorporan más mano de obra al quitar competitividad externa a estos productos. El propio proceso de estabilización, aunado probablemente al impacto de exportaciones ilegales (y por tanto no registradas) de hojas o derivados de coca sobre el tipo de cambio, habría cerrado la vía a un crecimiento de las exportaciones de bienes manufacturados. Cabe anotar en segundo lugar que las exportaciones peruanas se componen sobre todo de bienes primarios (31.5\% del total en 2002) y de bienes industrializados de bajo valor agregado (bienes tradicionales y con elevadas economías de escala y alta intensidad en recursos naturales, respectivamente $36.5 \%$ y $29.9 \%$ del total en este mismo año). En contraste, las exportaciones de bienes difusores de progreso técnico solo constituían $1.5 \%$ de las exportaciones peruanas (cuadro 5).
Aún cuando la diversidad de productos exportados habría protegido al país de los efectos de variaciones brutales en el precio de cada uno de estos bienes, la especialización primaria implica ubicarse en un segmento del mercado mundial a menudo considerado como menos propicio al crecimiento económico, sujeto a fuertes fluctuaciones de precios y al deterioro de sus términos de intercambio en relación con bienes industrializados más sofisticados, precisamente la misma inserción internacional desfavorable que el proceso de ISI aspiraba a modificar. El ejemplo de países que basaron su desarrollo en recursos naturales, como es el caso de Australia o de los europeos nórdicos como Suecia y Finlandia, y más recientemente, del vecino sureño de Perú, Chile, muestra que aún en estas condiciones el desarrollo es factible. Ahora bien, estos casos exitosos son lo bastante escasos para sugerir que las probabilidades de quedarse en el sub-

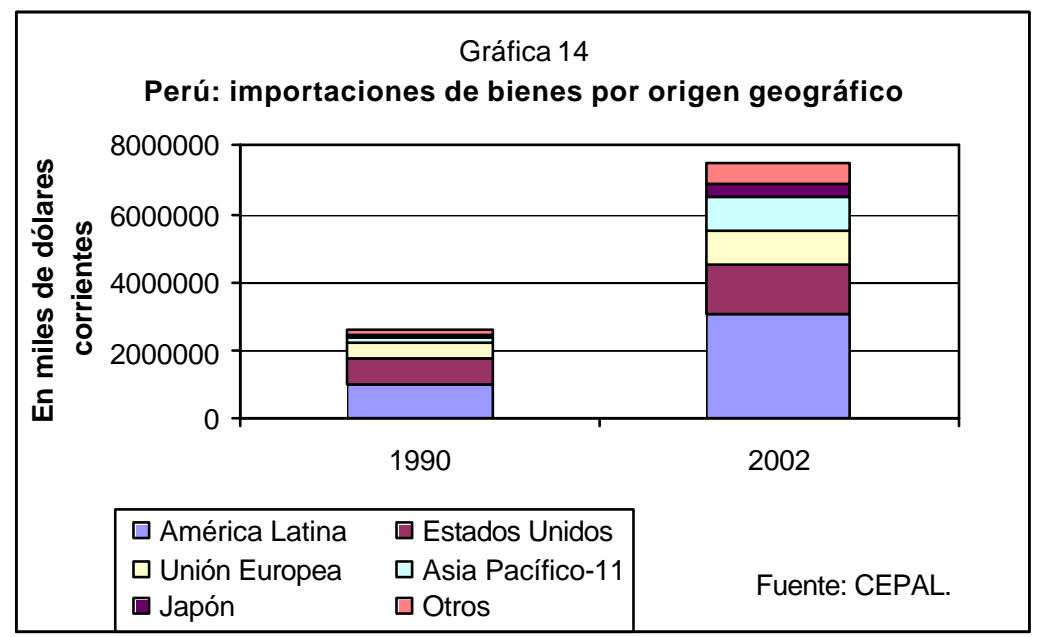


desarrollo son muy altas. De hecho el FMI, en un estudio reciente en el cual discute las limitaciones al crecimiento y al desempeño exportador en Perú, señala que la especialización del país en exportaciones basadas en recursos naturales constituiría un "desafío importante mas no infranqueable". ${ }^{37}$

Otras barreras a una mayor inversión y mayores exportaciones mencionadas en el estudio estarían constituidas por una serie de factores de orden institucional y estructural, que cabría reformar para fortalecer el desempeño exportador. Entre éstos sobresalen el marco jurídico, donde prevalecen la incertidumbre en el respecto de los contratos y las debilidades en la impartición de justicia, los elevados costos del financiamiento interno, así como las limitaciones de la infraestructura de transporte y de puertos que afectan negativamente la inversión al elevar notablemente los costos de las empresas.

Por otro lado, la composición geográfica del comercio exterior peruano muestra que éste se encuentra bastante diversificado y vinculado a mercados importantes (gráficas 13 y 14): los primeros mercados de exportación de los productos peruanos son Estados Unidos y la Unión Europea (ambos un cuarto de las exportaciones) seguidos de once países de Asia Pacífico y Japón (alrededor de 19\% en 2002); finalmente, la región latinoamericana recibía cerca de $17 \%$ del valor exportado por Perú. De este conjunto de mercados, el más dinámico es sin duda el asiático, y en particular China, cuya alta demanda de bienes primarios ha fortalecido tanto los precios como los volúmenes exportados de Perú.

\section{Conclusión}

Este texto se ha centrado en presentar una interpretación de la evolución macroeconómica de Perú de las últimas tres décadas. La larga crisis del modelo de industrialización por sustitución de importaciones (1975-1990) y la pobre gestión que hicieron de ella los sucesivos gobiernos, implicaron para este país desórdenes macroeconómicos extremos, así como agudas tensiones sociales y políticas. La adopción de un nuevo modelo económico en los años noventa, inicialmente favorecida por un entorno internacional de abundancia de fondos, permitió restablecer los equilibrios macroeconómicos y reanudar el proceso de crecimiento económico más no permitió cerrar la "brecha social": la gran mayoría de población peruana se encuentra empobrecida de manera duradera y los escasos frutos del crecimiento se han concentrado en una estrecha franja de ésta.

Cual sea el esquema de crecimiento adoptado, hemos visto que Perú no ha podido modificar el carácter de su inserción internacional de exportador de bienes primarios. Incluso algunos desarrollos recientes, como el crecimiento de las exportaciones de textiles y prendas de vestir hacia Estados Unidos, asociados a un acuerdo de comercio preferencial de la región andina con este país, están puestos en duda, debido a la finalización del acuerdo multifibras y la mayor competencia china en este mercado.

Las reformas implicaron el regreso a un patrón de industrialización (bienes de consumo y bienes intermedios intensivos en recursos naturales) que prevalecía antes del esfuerzo de ISI. Finalmente, las dificultades vinculadas a la especialización primario-exportadora quedan enteras, y el esfuerzo de cambio institucional y estructural a realizar, más descomunal que antes, debido al enorme retraso acumulado durante la larga crisis.

\section{Referencias adicionales}

Durand, Francisco (2003) Riqueza económica y pobreza política. Reflexiones sobre las élites del poder en un país inestable. Pontificia Universidad Católica del Perú.

\section{Notas}

1 La población peruana representa algo más de la cuarta parte de la mexicana, mientras que el territorio del país equivale a $65 \%$ del territorio mexicano.

2 Datos comparativos en línea del Banco Mundial.

3 cIA, The World Factbook, Peru, en http://www.cia.gov/ cia/publications/factbook/geos/pe.html\#Econ. 
4 Thorp, Rosemary y Geoffrey Bertram. Peru 1890-1977: Growth and Policy in an Open Economy. Macmillan Press Ltd, 1978, disponible en español bajo el título Perú 1890-1977: crecimiento y políticas en una economía abierta, Mosca Azul Ed., Fundación Friedrich Ebert y Universidad de Pacífico, Lima, 1985.

5 Ésta fue la crisis más aguda que sufrió Perú, pues el país fue ocupado y perdió parte de su territorio sureño, rico en minerales.

6 Op. cit., Throp, p. 487 (versión en español).

7 Este nombre se refiere al efecto que produjo en la estructura económica de los Países Bajos y en particular en la competitividad externa de los demás sectores productivos, la explotación de importantes yacimientos de gas natural descubiertos en la segunda mitad del siglo veinte y las exportaciones de este producto primario.

8 Fitz Gerald, E.V.K.,La economía política del Perú, 19561978. Desarrollo económico y reestructuración del capital, Instituto de estudios Peruanos, 1981, p. 384-385.

9 Jiménez, Félix, Giovanna Aguilar y Javier Kapsoli, De la industrialización proteccionista a la desindustrialización neoliberal, Consorcio de invetigación económica y Pontificia Universidad Católica del Perú, 1999, p. 25.

10 Thorp, Rosemary y Geoffrey Bertram.Perú 1890-1977: crecimiento y políticas en una economía abierta, op. cit., p. 409.

11 Ibid., cuadro 13.5, p. 411.

12 Dancourt, Óscar, "Reforma neoliberal y política macroeconómica en el Perú", Revista de la CEPAL, núm. 67, abril de 1999, Santiago de Chile, pp. 49-70. La construcción del sector público productivo se hizo en parte sobre la base de la nacionalización de los intereses extranjeros, particularmente en la industria extractiva.

13 Ugarteche, Óscar, El Estado deudor. Economía política de la deuda: Perú y Bolivia, 1968-1984. Instituto de Estudios Peruanos, 1986, p. 199.

14 La maturación extemporánea de algunos proyectos mineros constituye una de las causas de esta crisis temprana.

15 Jiménez, Félix, Giovanna Aguilar y Javier Kapsoli, De la industrialización proteccionista a la desindustrialización neoliberal, op. cit., p. 24.

16 Ibid., p. 21.

17 Ibid., p. 23.

18 En 1975 el arancel promedio en las industrias productoras de bienes de capital, de bienes intermedios y de bienes de consumo era respectivamente de 55, 69 y $107 \%$, ibid., p. 28.

19 Ibid., p. 10.

20 Dancourt, Óscar, "Reforma neoliberal y política macroeconómica en el Perú", op. cit.,

21 Jiménez, Félix, Giovanna Aguilar y Javier Kapsoli, De la industrialización proteccionista a la desindustrialización neoliberal, op. cit., p. 30.
22 Véase Lora, Eduardo, "Structural Reforms in Latin America. What has been reformed and how to measure it?", Working Paper $n^{\circ} 466$, Banco Interamericano de Desarrollo, diciembre de 2001, anexo 2.

23 Jiménez, Félix, Giovanna Aguilar y Javier Kapsoli, De la industrialización proteccionista a la desindustrialización neoliberal, op. cit., p. 28.

24 Ledesma, Patricia, "The Peruvian Experience with Financial Liberalization, 1990-1999", texto presentado en el congreso de la Latin American Studies Association, Washington D.C., septiembre de 2001, p. 6.

25 FMI, "Perú: Selected Issues", ImF Staff Country Report $n^{o}$ 98 197, Washington D.C., septiembre de 1998, p. 6.

26 Jiménez, Félix, Giovanna Aguilar y Javier Kapsoli, De la industrialización proteccionista a la desindustrialización neoliberal, op. cit., p. 31.

27 El índice de tipo de cambio real efectivo calculado por la CEPAL, con base 100 en 2000, establece el tipo de cambio real de la moneda peruana en 92.8 en 1995, en 101.8 en 1999 y en 102.9 en 2004 (cifra preliminar), véase CEPAL, Balance preliminar de las economías de América del Sur y del Caribe 2003-2004, Apéndice estadistico, cuadro A-21, p. 165.

28 Jiménez, Félix, Giovanna Aguilar y Javier Kapsoli, De la industrialización proteccionista a la desindustrialización neoliberal, op. cit., p. 64.

29 CEPAL, Balance preliminar de las economías de América del Sur y del Caribe 2003-2004, op. cit., cuadro A-24, p. 168.

30 Si dejamos de lado el año 1979, excepcional por las altas cotizaciones internacionales de las materias primas, este puesto de la balanza de pagos nunca es superavitario.

31 Cuando la inflación es muy elevada y en ausencia de algún mecanismo de indización, la recaudación fiscal tiende a bajar, debido al plazo entre el momento en el cual se generan los ingresos privados que constituyen la base del impuesto y el momento en el cual los contribuyentes deben pagar su impuesto: cuanto más largo el plazo y más alta la inflación, más valor real pierden los ingresos fiscales.

32 Banco Mundial, World Development Indicators 2002.

33 Dancourt, Óscar, "Desafíos de la reactivación económica”, Economía y sociedad, núm. 48, cIEs, abril de 2003, consultado en http://consorcio.org/CIES/html/pdfs/bol48/ Dancourt.pdf.

34 Iguiñiz, Javier, "Transición democrática: ¿continuidad o cambio?", Economía y sociedad, núm. 48, cIEs, abril de 2003, consultado en http://consorcio.org/CIES/html/pdfs/ bol48/Iguiniz.pdf.

35 Ibid., cuadro 3, p. 35.

36 CEPAL, Balance preliminar de las economías de América del Sur y del Caribe 2003-2004, op. cit., cuadro A-22, p. 166.

37 FMI, "Perú: Selected Issues", IMF Country Report no 04 / 156, Washington D.C., mayo de 2004, p. 33. T:- 